Research Paper

\title{
Effects of Diet Intervention on Body Composition in the Elderly with Chronic Kidney Disease
}

Kai-Yin Hung, ${ }^{1}$ Terry Ting-Yu Chiou ${ }^{2}$, Chien-Hsing Wu ${ }^{3}$, Ying-Chun Liao ${ }^{3}$, Chian-Ni Chen ${ }^{1}$, Pei-Hsin Yang ${ }^{1}$, Hung-Jen Wang ${ }^{1,4}$, Chien-Te Lee ${ }^{3 凶}$

1. Division of Nutrition, Kaohsiung Chang Gung Memorial Hospital, Kaohsiung, Taiwan;

2. Division of Nephrology, Department of Internal Medicine, Kaohsiung Chang Gung Memorial Hospital, Chang Gung University College of Medicine and Chung Shan Medical University School of Medicine, Taiwan;

3. Division of Nephrology, Department of Internal Medicine, Kaohsiung Chang Gung Memorial Hospital and Chang Gung University College of Medicine, Kaohsiung, Taiwan;

4. Division of Urology, Department of Surgery, Kaohsiung Chang Gung Memorial Hospital and Chang Gung University College of Medicine, Kaohsiung, Taiwan.

$\square$ Corresponding author: 123, Ta-Pei Raod, Niao-Sung District, 833 Kaohsiung City, Taiwan E-mail: chientel@gmail.com; Tel..+ 886-7-7317123 EXT 8306; Fax: $+886-7-7322402$

(c) Ivyspring International Publisher. This is an open access article distributed under the terms of the Creative Commons Attribution (CC BY-NC) license (https://creativecommons.org/licenses/by-nc/4.0/). See http://ivyspring.com/terms for full terms and conditions.

Received: 2017.02.26; Accepted: 2017.06.18; Published: 2017.07.18

\begin{abstract}
Objective: It has been uncertain that low protein diet for patients with chronic kidney disease (CKD) may predispose to malnutrition. The study aimed to investigate the effects of low protein diet on body composition of CKD patients and analyze the influence of age.

Methods: Patients with glomerular filtration rate less than $45 \mathrm{~mL} / \mathrm{min} / 1.73 \mathrm{~m}^{2}$ including 103 elderly (70.7 \pm 6.9 years old $)$ and 56 non-elderly $(49.8 \pm 9.1$ years old $)$ CKD patients were enrolled. All patients were educated by dietitians to take low protein diet and were followed up regularly every three months. Their demographic data, underlying disease and body mass index (BMI) were reviewed and recorded. Results of body composition measurement and laboratory tests were collected every three months for one year.

Results: At baseline, the distribution of body composition was similar in non-elderly patients between non-low and low protein groups. In the elderly, patients in low protein group had higher fat and lower muscle percentage. In one-year follow-up, non-elderly patients did not present significant changes in their BMI, serum albumin level and body compositions in both protein groups. Non-low protein group in elderly patients had significant decrease in BMI and estimated glomerular filtration rate (eGFR) after 12 months (both $\mathrm{p}<0.05$ ). Determination in body composition showed decrease in fat and increase in muscle component. In low protein group, their BMI was decreased and eGFR was not influenced. Fat component was decreased and muscle percentage was increased in one-year follow-up.

Conclusions: In elderly CKD patients, low protein diet maintained good nutritional status and muscle mass was preserved.
\end{abstract}

Key words: Body composition, chronic kidney disease, low protein diet, muscle mass.

\section{Introduction}

Patients with chronic kidney disease (CKD) are usually recommended to maintain low protein diet to slow down renal function deterioration [1]. It is well-recognized that progressive decline of renal function with aging is common [2]. However, higher protein intake can prevent protein-energy malnutrition in the elderly. Therefore, how to adjust protein intake appropriately for the elderly with CKD is an important issue. For elderly population without $\mathrm{CKD}$, the recommended protein intake is over 0.8 $\mathrm{g} / \mathrm{kg} /$ day [3]. It has been estimated that 10 to $35 \%$ of elderly people take protein below minimal requirement $(0.7 \mathrm{~g} / \mathrm{kg} \mathrm{BW} /$ day $)$ [4]. In order to minimize the progression of sarcopenia, increased protein intake to $1.0-1.3 \mathrm{~g} / \mathrm{kg} /$ day was suggested [5]. In a national-wide study, glomerular filtration rate 
(GFR) less than $30 \mathrm{~mL} / \mathrm{min} / 1.73 \mathrm{~m}^{2}$ was an independent factor associated with malnutrition for older adults [6]. Collectively, it would be better to individualize the amount of protein intake by close monitoring renal function and muscle wasting status in the elderly. Previous studies of body compositions of patients with CKD are usually with small numbers and mostly included patients with age less than $60[7$, 8]. The concern on safety of low protein diet for elderly patients is raised but only little information is available.

Anorexia, dietary restriction, acidosis, and inflammation in CKD patients can increase the risks of cachexia and protein-energy wasting syndrome [9]. Muscle wasting is associated with increased mortality in patients with chronic illness [10-12]. Therefore, it is indicated to assess body composition and monitor muscle mass in these patients. Serial body composition measurements can detect changes in muscle mass and provide additional information of nutritional status than common nutritional markers, such as body weight, body mass index (BMI), and serum albumin [12, 13]. Dual energy X-ray absorptiometry (DXA) is the gold standard for body composition assessment. However, the machine occupies large space with high cost, and is not recommended for routine clinical use.

In the present study, bioelectrical impedance analysis (BIA) with tetra-polar impedance meter was employed for the determination of body composition. We analyzed the effects of low protein diet on body compositions of CKD patients. We also compared the alterations of body composition between elderly and non-elderly patients.

\section{Patients and methods}

Patients with eGFR $\leq 45 \mathrm{~mL} / \mathrm{min} / 1.73 \mathrm{~m}^{2}$ (CKD stage $3 b$ ) regularly followed up in nephrology clinics were recruited. Patients were excluded if they had chronic heart failure (New York Heart Association Functional Classification System, $\geq$ stage III) or active infection, and any of which might affect dietary intake, such as swallowing difficulty or cancer under treatments. Subjects with contraceptive devices, metallic transplant, liquid filled catheter, or pregnancy were excluded as well. This study was approved by Chang Gung Medical Foundation Institutional Review Board (101-3599B). All participants involved gave written informed consent.

Demographic data including gender, age, body weight, body height, BMI were collected. Diabetes mellitus (DM) was defined as patients who were receiving oral anti-diabetic or insulin treatment; with fasting blood sugar $\geq 126 \mathrm{mg} / \mathrm{dL}$ or random blood sugar $\geq 200 \mathrm{mg} / \mathrm{dL}$ with associated symptoms. Blood pressure was measured at every visit. Laboratory data including serum creatinine, albumin, hemoglobin, glycosylated hemoglobin, total cholesterol, high-density lipoprotein, low-density lipoprotein, and triglyceride were measured at baseline and one year later. The eGFR was calculated by using Modification of Diet in Renal Disease (MDRD) formula [14]. The participants received dietary counselling and their body compositions were measured every three months for one year. The registered dietitians calculated the energy and protein intake of these CKD patients from each interview. Dietary counselling was individualized and focused on educating and advising patients about food portions, selections and preparations. For participants' understanding and encouraging them doing exercise, the registered dietitians interpreted the results of body composition measurement to all participants. The low protein group was defined as average protein intake $\leq 0.8 \mathrm{~g}$ protein / kg/day [15]. The rest of enrolled patients were defined as non-low protein group. Age greater than 60 was defined as the elderly group in the present study.

Waist circumference was measured at the midway between the lowest rib and iliac crest. The participants were instructed to fast for 4-hours before body composition measurement. The assessment of body composition followed the manufactory's protocol of the bioelectrical impedance analysis (BIA) (ioi 353, Jawon Medical, S. Korea). The BIA device measured five body segments (right arm, right leg, left arm, left leg, and trunk) via tetra-polar electrode method using 8 touch electrodes. Appendicular skeletal muscle mass (ASM) index is calculated as muscle of limbs measured by BIA divided by height squared $\left(\mathrm{kg} / \mathrm{m}^{2}\right)[16,17]$.

\section{Statistical methods}

All statistical analyses were performed using statistical SPSS version 19 software (IBM Corporation). Data were presented as mean \pm standard deviation or percentage as appropriate. Continuous variables were compared using ANOVA or the Mann-Whitney $U$ test. Comparison of body compositions at baseline and every 3 months was analyzed by paired $t$ test or Wilcoxon test. A p value < 0.05 was considered as statistically significant.

\section{Results}

A total of CKD patients including 103 elderly patients and 56 non-elderly patients were recruited. Table 1 displays their baseline characteristics of non-low protein and low protein groups in different age groups. The mean age of elderly CKD patients was significantly greater than the non-elderly group 
(70.2 \pm 6.8 vs. $50.7 \pm 8.9$ and $70.2 \pm 7.3$ vs. $46.8 \pm 9.5$ in non-low and low protein groups respectively, both $\mathrm{p}$ $<0.001$ ). Diabetes accounts for $23 \%$ of enrolled patients. In elderly patients, protein and energy intake were significantly lower in low protein group than non-low protein group $(0.71 \pm 0.06 \mathrm{~g} / \mathrm{kg}$ and $23.3 \pm 2.5$ $\mathrm{kcal} / \mathrm{kg}$ vs. $1.01 \pm 0.17 \mathrm{~g} / \mathrm{kg}, 29.0 \pm 4.2 \mathrm{kcal} / \mathrm{kg}$, both $\mathrm{p}$ $<0.001$ ). There were no significant differences in blood pressure, BMI, waist circumference and eGFR. The biochemical data was similar between two groups. Elderly patients in low protein group had higher body fat percentage and lower muscle percentage than non-low protein group $(p<0.05)$. No difference was noted in their ASM index. In the non-elderly patients, low protein group had lower protein intake and energy intake (both $\mathrm{p}<0.001$ ). Their body compositions did not differ between two protein groups. We further compared elderly and non-elderly patients in either non-low or low protein groups. In non-low protein patients, diastolic blood pressure was higher in non-elderly patients $(p<0.05)$. In the low protein groups, non-elderly patients had higher serum albumin levels and lower total cholesterol levels than the elderly patients (both $\mathrm{p}<$ 0.05). Comparison in body composition revealed non-elderly patients had lower body fat percentage and higher muscle percentage than the elderly (both $p$ $<0.05$ ).
Table 2 represents the baseline and 1-year follow-up data of non-elderly patients. In one year, we found there was significant decline of eGFR in non-low protein group while the eGFR was not influenced in low protein group. The biochemical data and body composition did not change significantly in 1-year follow up either in non-low or low protein groups. Table 3 presents the changes in elderly CKD patients. There was significant decrease in BMI and eGFR in the non-low protein group after 1-year follow-up. Modest but significant increase in albumin level was noted. Their hemoglobin level was decreased. Measurement in body composition indicated that a significant decrease in fat and increase in muscle component after 1 year (both $\mathrm{p}<$ 0.05). In low protein group, their BMI was decreased and levels of serum albumin and triglyceride were increased significantly. Comparison in body composition revealed decrease in fat percentage, including total body and trunk fat. The muscle component was increased ( $p<0.05)$. Similar to the results of comparison in baseline, after 1 year, there were significant differences between non-low and low protein groups in fat and muscle distribution. Patients in low protein group had higher percentage of fat and lower percentage of muscle (both $\mathrm{p}<0.05$ ). There was no significant change in ASM index after 1-year follow-up in both groups.

Table 1. Comparisons of baseline characteristics and body composition between non-low protein and low protein CKD patients in different age groups.

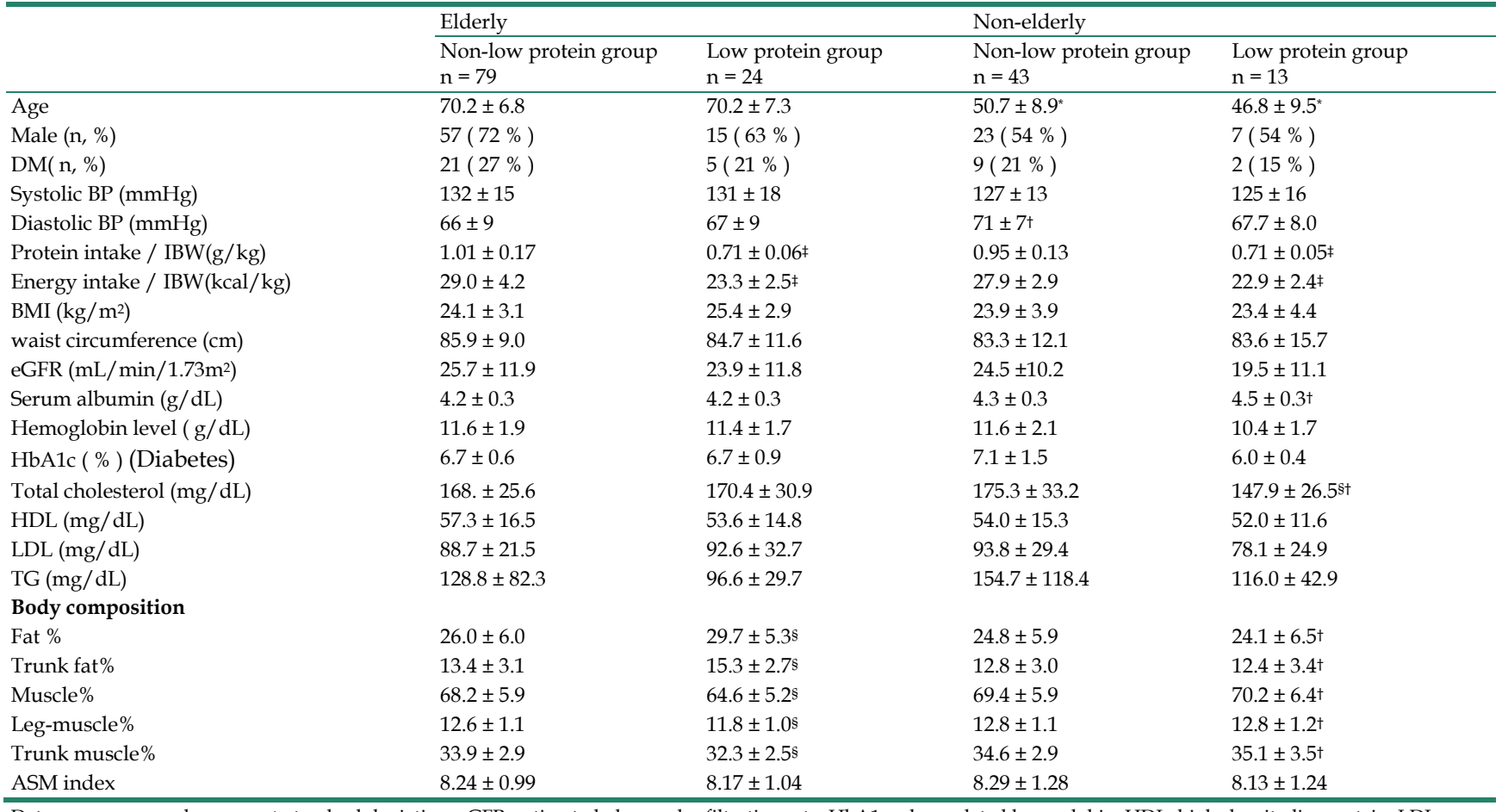

Data were expressed as mean \pm standard deviation. eGFR, estimated glomerular filtration rate; HbA1c, glycosylated hemoglobin; HDL, high-density lipoprotein; LDL, low-density lipoprotein; TG, triglyceride; BMI, body mass index; ASM index, appendicular skeletal muscle mass index.

${ }^{*} \mathrm{p}<0.001$ elderly vs. non-elderly. $₫ \mathrm{p}<0.001$ non-low protein vs. low protein group. $\dagger \mathrm{p}<0.05$ elderly vs. non-elderly. $§ \mathrm{p}<0.05$ non-low protein vs. low protein group. 
Table 2. Comparisons of characteristics and body compositions of non-elderly patients in different protein intake groups at baseline and 1-year follow-up.

\begin{tabular}{|c|c|c|c|c|}
\hline & \multicolumn{2}{|c|}{ Non-low protein group, $n=43$} & \multicolumn{2}{|c|}{ Low protein group, $\mathrm{n}=13$} \\
\hline & Baseline & 1-year follow-up & Baseline & 1-year follow-up \\
\hline $\mathrm{BMI}\left(\mathrm{kg} / \mathrm{m}^{2}\right)$ & $23.9 \pm 3.9$ & $24.0 \pm 3.7$ & $23.4 \pm 4.4$ & $23.3 \pm 4.6$ \\
\hline waist circumference $(\mathrm{cm})$ & $83.3 \pm 12.1$ & $81.6 \pm 9.4$ & $83.6 \pm 15.7$ & $85.1 \pm 15.8$ \\
\hline $\mathrm{eGFR}\left(\mathrm{mL} / \mathrm{min} / 1.73 \mathrm{~m}^{2}\right)$ & $24.5 \pm 10.2$ & $21.9 \pm 11.3^{*}$ & $19.5 \pm 11.1$ & $19.3 \pm 14.0$ \\
\hline Serum albumin (mg/dL) & $4.3 \pm 0.3$ & $4.5 \pm 0.4$ & $4.5 \pm 0.3$ & $4.4 \pm 0.3$ \\
\hline Hemoglobin level ( g/dL) & $11.6 \pm 2.1$ & $12.7 \pm 5.8$ & $10.4 \pm 1.7$ & $10.9 \pm 2.3$ \\
\hline HbA1c ( \% ) (DM only) & $7.1 \pm 1.5$ & $6.6 \pm 1.1$ & $6.0 \pm 0.4$ & $6.0 \pm 0.6$ \\
\hline Total cholesterol (mg/dL) & $175.3 \pm 33.2$ & $161.5 \pm 47.9$ & $147.9 \pm 26.5$ & $142.5 \pm 28.0$ \\
\hline HDL (mg/dL) & $54.0 \pm 15.3$ & $53.6 \pm 15.1$ & $52.0 \pm 11.6$ & $46.2 \pm 6.1$ \\
\hline LDL (mg/dL) & $93.8 \pm 29.4$ & $86.0 \pm 33.9$ & $78.1 \pm 24.9$ & $84.0 \pm 30.7$ \\
\hline $\mathrm{TG}(\mathrm{mg} / \mathrm{dL})$ & $154.7 \pm 118.4$ & $182.8 \pm 241.7$ & $116.0 \pm 42.9$ & $105.8 \pm 35.8$ \\
\hline \multicolumn{5}{|l|}{ Body composition } \\
\hline Fat $\%$ & $24.8 \pm 5.9$ & $24.7 \pm 5.9$ & $24.1 \pm 6.5$ & $24.0 \pm 7.2$ \\
\hline Trunk fat \% & $12.8 \pm 3.0$ & $12.7 \pm 3.0$ & $12.4 \pm 3.4$ & $12.3 \pm 3.7$ \\
\hline Muscle \% & $69.4 \pm 5.9$ & $69.5 \pm 5.9$ & $70.2 \pm 6.4$ & $70.3 \pm 7.2$ \\
\hline Leg-muscle \% & $12.8 \pm 1.1$ & $12.8 \pm 1.2$ & $12.8 \pm 1.2$ & $12.9 \pm 1.3$ \\
\hline Trunk muscle \% & $34.6 \pm 2.9$ & $34.6 \pm 2.8$ & $35.1 \pm 3.5$ & $35.1 \pm 3.7$ \\
\hline ASM index & $8.29 \pm 1.28$ & $8.54 \pm 1.85$ & $8.13 \pm 1.24$ & $8.08 \pm 1.08$ \\
\hline
\end{tabular}

Data were expressed as mean \pm standard deviation. ASM index, appendicular skeletal muscle mass index; BMI, body mass index.

${ }^{*} \mathrm{p}<0.05$ compared with baseline.

Table 3. Comparisons of characteristics and body compositions of elderly patients in different protein intake groups at baseline and 1-year follow-up.

\begin{tabular}{|c|c|c|c|c|}
\hline & \multicolumn{2}{|c|}{ Non-low protein group, $\mathrm{n}=79$} & \multicolumn{2}{|c|}{ Low protein group, $\mathrm{n}=24$} \\
\hline & Baseline & 1-year follow-up & Baseline & 1-year follow-up \\
\hline BMI $\left(\mathrm{kg} / \mathrm{m}^{2}\right)$ & $24.1 \pm 3.1$ & $23.9 \pm 3.1^{*}$ & $25.4 \pm 2.9$ & $24.8 \pm 2.8^{*}$ \\
\hline waist circumference $(\mathrm{cm})$ & $85.9 \pm 9.0$ & $85.3 \pm 9.0$ & $84.7 \pm 11.6$ & $86.2 \pm 10.5$ \\
\hline $\mathrm{eGFR}\left(\mathrm{mL} / \mathrm{min} / 1.73 \mathrm{~m}^{2}\right)$ & $25.7 \pm 11.9$ & $24.5 \pm 13.2^{*}$ & $23.9 \pm 11.8$ & $23.2 \pm 13.6$ \\
\hline Serum albumin (mg/dL) & $4.2 \pm 0.3$ & $4.3 \pm 0.4^{*}$ & $4.2 \pm 0.3$ & $4.3 \pm 0.3^{*}$ \\
\hline Hemoglobin level (g/dL) & $11.6 \pm 1.9$ & $11.3 \pm 2.0^{*}$ & $11.4 \pm 1.7$ & $11.2 \pm 1.5$ \\
\hline HbA1c ( \% ) (DM only) & $6.7 \pm 0.6$ & $6.5 \pm 0.7$ & $6.7 \pm 0.9$ & $6.9 \pm 0.9$ \\
\hline Total cholesterol (mg/dL) & $168 . \pm 25.6$ & $168.3 \pm 32.0$ & $170.4 \pm 30.9$ & $153.4 \pm 28.8$ \\
\hline HDL (mg/dL) & $57.3 \pm 16.5$ & $56.5 \pm 20.8$ & $53.6 \pm 14.8$ & $53.8 \pm 17.8$ \\
\hline $\mathrm{LDL}(\mathrm{mg} / \mathrm{dL})$ & $88.7 \pm 21.5$ & $90.6 \pm 25.6$ & $92.6 \pm 32.7$ & $78.3 \pm 26.3$ \\
\hline $\mathrm{TG}(\mathrm{mg} / \mathrm{dL})$ & $128.8 \pm 82.3$ & $114.0 \pm 61.4$ & $96.6 \pm 29.7$ & $126.9 \pm 57.0^{*}$ \\
\hline \multicolumn{5}{|l|}{ Body composition } \\
\hline Fat $\%$ & $26.0 \pm 6.0$ & $25.4 \pm 6.6^{*}$ & $29.7 \pm 5.3$ & $28.6 \pm 5.1^{* \dagger}$ \\
\hline Trunk fat $\%$ & $13.4 \pm 3.1$ & $13.1 \pm 3.4^{*}$ & $15.3 \pm 2.7$ & $14.7 \pm 2.6^{* \dagger}$ \\
\hline Muscle \% & $68.2 \pm 5.9$ & $68.8 \pm 6.5^{*}$ & $64.6 \pm 5.2$ & $65.7 \pm 5.0^{*}+$ \\
\hline Leg-muscle \% & $12.6 \pm 1.1$ & $12.7 \pm 1.3$ & $11.8 \pm 1.0$ & $12.0 \pm 1.0^{*}+$ \\
\hline Trunk muscle $\%$ & $33.9 \pm 2.9$ & $34.2 \pm 3.1^{*}$ & $32.3 \pm 2.5$ & $32.8 \pm 2.3^{*}$ \\
\hline ASM index & $8.24 \pm 0.99$ & $8.23 \pm 1.05$ & $8.17 \pm 1.04$ & $8.14 \pm 1.18$ \\
\hline
\end{tabular}

Data were expressed as mean \pm standard deviation. ASM index, appendicular skeletal muscle mass index; BMI, body mass index.

${ }^{*} \mathrm{p}<0.05$ compared with baseline.

$\dagger \mathrm{p}<0.05$ non-low protein vs. low protein group after 1-year follow-up.

We further analyzed the serial changes of muscle percentage in every 3 months body composition measurements. As shown in figure 1, elderly CKD patients had lower muscle percentage than the non-elderly CKD patients. The percentage did not change significantly in non-elderly patients in oneyear follow-up. There was significant increase at 12 months measurement in the elderly patients.

\section{Discussion}

Our study clearly demonstrated that diet intervention with low protein therapy did not affect nutritional status in CKD patients. Furthermore, in elderly CKD patients, despite their progressive decrease in BMI, low protein diet was associated with increased serum albumin level and their muscle mass were preserved. In 1-year follow-up, there was a significant decline of eGFR in patients with non-low protein intake.

Therefore, low protein diet is the recommended nutritional therapy for CKD patients especially for those with eGFR less than $45 \mathrm{~mL} / \mathrm{min} / 1.73 \mathrm{~m}^{2}$. However, the potential risk of protein-energy wasting from dietary protein restriction prompted researchers to investigate the effect of low protein diet on nutrition status. Most studies analyzed the effect of 
low protein diet on body composition focused on middle-aged patients. These studies indicated that low protein diet did not have adverse effects on body composition despite patients usually had weight loss in the first six months then recovered eventually [18, 19]. With constant BMI, body fat percentage increased with aging [20]. In our study, comparing with non-elderly CKD patients, the elderly had higher percentage of fat. We further compared the alterations of body composition and found no significant change in the non-elderly patients. In the elderly CKD patients, low protein diet preserved muscle mass, and serum albumin was even increased.

It has been reported that elderly with higher BMI such as $25-35 \mathrm{~kg} / \mathrm{m}^{2}$ had lower mortality [21], indicating elderly should maintain higher BMI. In another study, Lu et al. found the beneficial effect of high BMI was attenuated in patients with eGFR $<30$ $\mathrm{mL} / \mathrm{min} / 1.73 \mathrm{~m}^{2}$ [22]. Therefore, whether higher BMI is associated with better outcome in CKD patients remains inconclusive. In non-CKD population, elderly with higher skeletal muscle mass index rather than BMI were associated with lower mortality [23]. In CKD patients, decreased abdominal adiposity together with lower waist circumferences and lower trunk fat, were associated with improved systemic inflammation and lower mortality [24-26]. In a longitudinal follow-up study on healthy elderly with stable energy intake and body weight, decrease in physical activity can cause progressive decrease in fat-free mass and increase in fat mass [27].

Previous studies have shown for the elderly with age greater than 70 , unintended weight loss occurred even with disease absent $[28,29]$. In our study, BMI was decreased significantly in elderly CKD patients in one-year follow-up. Both non-low protein and low protein group had body fat percentages decreased and muscle percentages increased. Apparently, these changes were not observed in the non-elderly patients. This finding indicated that aging process plays a key role in affecting body composition irrespective of protein intake. Nevertheless, whether the decline of renal function during aging contributes to the above change in BMI as well as body composition is unclear. Determination of body composition helps providing important information that elderly CKD patients both in non-low or low protein group can maintain muscle mass. Hence, patients with low protein intake still can preserve their muscle mass and serum albumin level was not reduced.

In the present study, we found patients with non-low protein diet were associated with significant decrease in eGFR during 1-year follow-up irrespective of their age. This finding highlights the importance of low protein intake in CKD patients. Compared with low protein group, patients with non-low protein diet had a drop of $3.5 \mathrm{~mL} / \mathrm{min} / 1.73 \mathrm{~m}^{2}$ in non-elderly CKD patients and it was $1.2 \mathrm{~mL} / \mathrm{min} / 1.73 \mathrm{~m}^{2}$ in the elderly group. In the low protein group, their eGFR change was decreased minimally. How to retard the progressive loss of residual renal function of CKD patients is primarily the utmost goal of CKD care [30]. Our results highlight the important role of diet intervention among CKD patients.

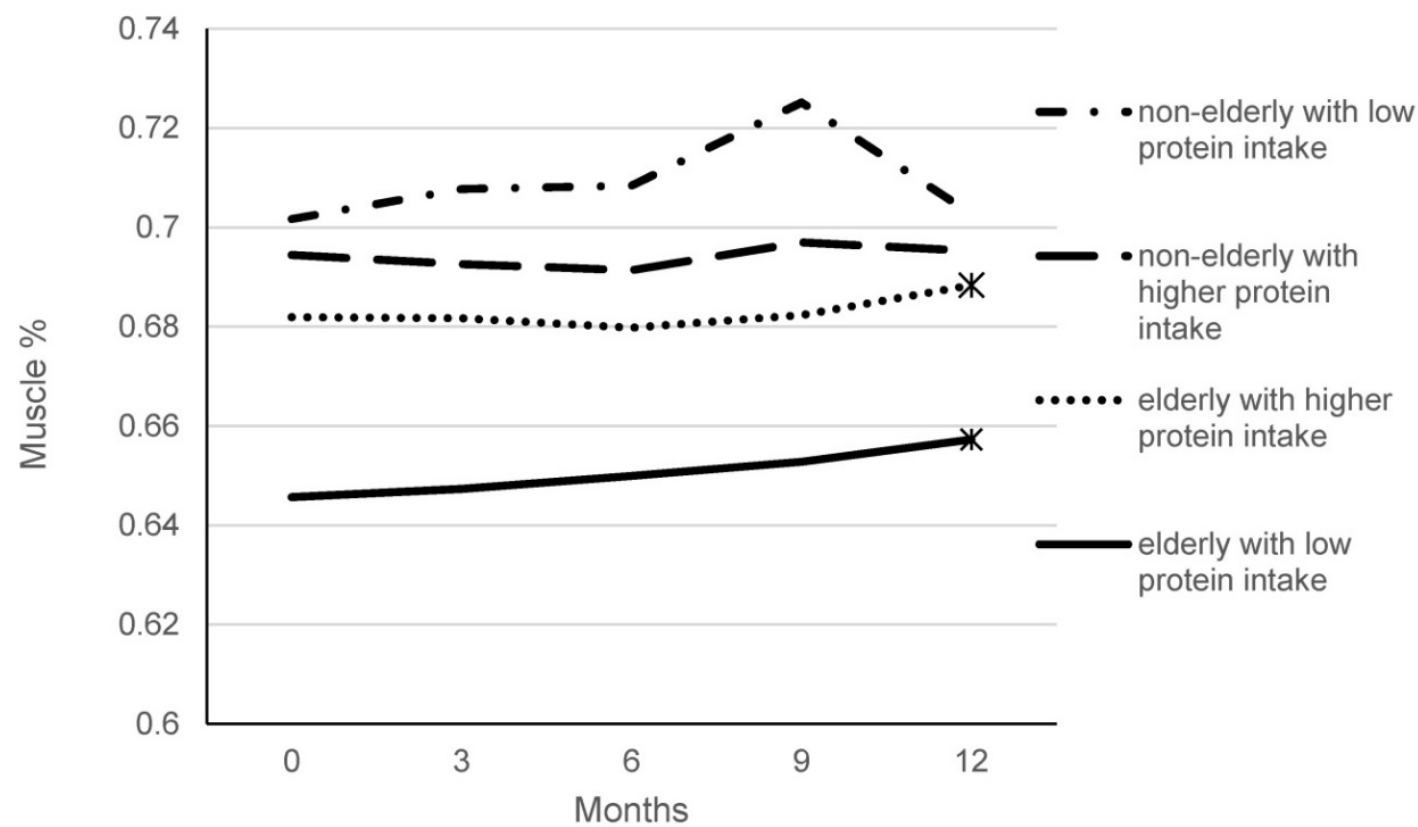

Figure 1. Changes of muscle percentage with 3-month intervals compared to baseline in one-year follow-up. $* \mathrm{p}<0.05$ compared with baseline. 
There are several limitations in our study. First, underestimation of energy intake may occur with the method of dietary history. Even with our method of estimating food portions during the dietary interview, calculation of fat intake may be imprecise. Second, the treatment of blood pressure, lipid profile and glycemic control of diabetic patients were not included for detail analysis. Thirdly, patients without diet intervention were not enrolled as control group. Lack of control group may underestimate the effect of low protein diet intervention. Lastly, 1-year follow-up period is rather short and a longer observation may help provide longitudinal changes in more aspects of CKD patients.

In conclusion, Low protein diet did not affect the nutritional status of elderly CKD patients. Their muscle mass was preserved with decreasing fat component. With the addition of body composition information provided by BIA device, diet intervention therapy can offer beneficial effects more effectively and appropriately in CKD patients.

\section{Acknowledgement}

The study was funded by research grants from Kaohsiung Chang Gung Memorial Hospital, CMRPG8B1121.

\section{Authors' contributions}

K-Y Hung, Terry Chiou, and C-T Lee, study design, data analysis and manuscript writing; $\mathrm{C}-\mathrm{H}$ Wu, K-T Hsu, Y-C Liao, C-N Chen, P-H Yang, and H-J Wan, clinical work and data collection. All authors read and approved the final manuscript.

\section{Competing Interests}

The authors have declared that no competing interest exists.

\section{References}

1. Kopple JD. National kidney foundation K/DOQI clinical practice guidelines for nutrition in chronic renal failure. American journal of kidney diseases : the official journal of the National Kidney Foundation. 2001; 37: S66-70.

2. Jones CA, McQuillan GM, Kusek JW, Eberhardt MS, Herman WH, Coresh J, et al. Serum creatinine levels in the US population: third National Health and Nutrition Examination Survey. American journal of kidney diseases : the official journal of the National Kidney Foundation. 1998; 32: 992-9.

3. Volkert D, Sieber CC. Protein requirements in the elderly. Int J Vitam Nutr Res. 2011; 81: 109-19.

4. Tieland M, Borgonjen-Van den Berg KJ, van Loon LJ, de Groot LC. Dietary protein intake in community-dwelling, frail, and institutionalized elderly people: scope for improvement. Eur J Nutr. 2012; 51: 173-9.

5. Morais JA, Chevalier S, Gougeon R. Protein turnover and requirements in the healthy and frail elderly. J Nutr Health Aging. 2006; 10: 272-83.

6. Garg AX, Blake PG, Clark WF, Clase CM, Haynes RB, Moist LM. Association between renal insufficiency and malnutrition in older adults: results from the NHANES III. Kidney Int. 2001; 60: 1867-74.

7. Leinig C, Pecoits-Filho R, Nascimento MM, Goncalves S, Riella MC, Martins C. Association between body mass index and body fat in chronic kidney disease stages 3 to 5, hemodialysis, and peritoneal dialysis patients. J Ren Nutr. 2008; 18: 424-9.

8. Campbell KL, Ash S, Davies PS, Bauer JD. Randomized controlled trial of nutritional counseling on body composition and dietary intake in severe CKD. American journal of kidney diseases : the official journal of the National Kidney Foundation. 2008; 51: 748-58.
9. Mak RH, Ikizler AT, Kovesdy CP, Raj DS, Stenvinkel P, Kalantar-Zadeh K. Wasting in chronic kidney disease. Journal of cachexia, sarcopenia and muscle. 2011; 2: 9-25.

10. Montano-Loza AJ, Meza-Junco J, Prado CM, Lieffers JR, Baracos VE, Bain VG, et al. Muscle wasting is associated with mortality in patients with cirrhosis. Clinical gastroenterology and hepatology : the official clinical practice journal of the American Gastroenterological Association. 2012; 10: 166-73, 73 e1.

11. Thibault R, Cano N, Pichard C. Quantification of lean tissue losses during cancer and HIV infection/AIDS. Current opinion in clinical nutrition and metabolic care. 2011; 14: 261-7.

12. Thibault R, Pichard C. The evaluation of body composition: a useful tool for clinical practice. Annals of nutrition \& metabolism. 2012; 60: 6-16.

13. Thibault R, Genton L, Pichard C. Body composition: why, when and for who? Clin Nutr. 2012; 31: 435-47.

14. Levey AS, Coresh J, Greene T, Marsh J, Stevens LA, Kusek JW, et al. Expressing the Modification of Diet in Renal Disease Study equation for estimating glomerular filtration rate with standardized serum creatinine values. Clinical chemistry. 2007; 53: 766-72.

15. KDOQI. KDOQI Clinical Practice Guidelines and Clinical Practice Recommendations for Diabetes and Chronic Kidney Disease. American journal of kidney diseases: the official journal of the National Kidney Foundation. 2007; 49: S12-154

16. Cruz-Jentoft AJ, Baeyens JP, Bauer JM, Boirie Y, Cederholm T, Landi F, et al. Sarcopenia: European consensus on definition and diagnosis: Report of the European Working Group on Sarcopenia in Older People. Age and ageing. 2010; 39: 412-23.

17. Fielding RA, Vellas B, Evans WJ, Bhasin S, Morley JE, Newman AB, et al. Sarcopenia: an undiagnosed condition in older adults. Current consensus definition: prevalence, etiology, and consequences. International working group on sarcopenia. Journal of the American Medical Directors Association. 2011; 12: 249-56.

18. Dumler F. Body composition modifications in patients under low protein diets. Journal of renal nutrition : the official journal of the Council on Renal Nutrition of the National Kidney Foundation. 2011; 21: 76-81.

19. Eyre S, Attman PO. Protein restriction and body composition in renal disease. Journal of renal nutrition : the official journal of the Council on Renal Nutrition of the National Kidney Foundation. 2008; 18: 167-86.

20. Prentice AM, Jebb SA. Beyond body mass index. Obesity reviews : an official journal of the International Association for the Study of Obesity. 2001; 2: 141-7.

21. Wu CY, Chou YC, Huang N, Chou YJ, Hu HY, Li CP. Association of body mass index with all-cause and cardiovascular disease mortality in the elderly. PloS one. 2014; 9: e102589.

22. Lu JL, Kalantar-Zadeh K, Ma JZ, Quarles LD, Kovesdy CP. Association of body mass index with outcomes in patients with CKD. Journal of the American Society of Nephrology : JASN. 2014; 25: 2088-96.

23. Kimyagarov S, Klid R, Levenkrohn S, Fleissig Y, Kopel B, Arad M, et al. Body mass index (BMI), body composition and mortality of nursing home elderly residents. Archives of gerontology and geriatrics. 2010; 51: 227-30.

24. Kramer H, Shoham D, McClure LA, Durazo-Arvizu R, Howard G, Judd S, et al. Association of waist circumference and body mass index with all-cause mortality in CKD: The REGARDS (Reasons for Geographic and Racial Differences in Stroke) Study. American journal of kidney diseases : the official journal of the National Kidney Foundation. 2011; 58: 177-85.

25. Carvalho LK, Barreto Silva MI, da Silva Vale B, Bregman R, Martucci RB, Carrero JJ, et al. Annual variation in body fat is associated with systemic inflammation in chronic kidney disease patients Stages 3 and 4: a longitudinal study. Nephrology, dialysis, transplantation : official publication of the European Dialysis and Transplant Association - European Renal Association. 2012; 27: 1423-8.

26. Hanks LJ, Tanner RM, Muntner P, Kramer H, McClellan WM, Warnock DG, et al. Metabolic subtypes and risk of mortality in normal weight, overweight, and obese individuals with CKD. Clinical journal of the American Society of Nephrology : CJASN. 2013; 8: 2064-71.

27. Luhrmann PM, Bender R, Edelmann-Schafer B, Neuhauser-Berthold M. Longitudinal changes in energy expenditure in an elderly German population: a 12-year follow-up. European journal of clinical nutrition. 2009; 63: 986-92.

28. Woo J, Ho SC, Sham A. Longitudinal changes in body mass index and body composition over 3 years and relationship to health outcomes in Hong Kong Chinese age 70 and older. Journal of the American Geriatrics Society. 2001; 49: 737-46.

29. Gaddey HL, Holder K. Unintentional weight loss in older adults. American family physician. 2014; 89: 718-22.

30. Levey AS, Coresh J, Balk E, Kausz AT, Levin A, Steffes MW, et al. National Kidney Foundation practice guidelines for chronic kidney disease: evaluation, classification, and stratification. Annals of internal medicine. 2003; 139: 137-47. 